\title{
Defined Imaging Enhancement Description
}

National Cancer Institute

\section{Source}

National Cancer Institute. Defined Imaging Enhancement Description. NCI Thesaurus.

Code C93771.

The textual representation for how an image is enhanced either physically or electronically. 